\title{
Renin is an angiotensin-independent profibrotic mediator: role in pulmonary
}

\section{fibrosis}

\author{
E. Montes*, V. Ruiz*, M. Checa*, V. Maldonado\#, J. Melendez-Zajgla", M. Montaño*, \\ R. Ordoñez-Razo ${ }^{+}$, J. Cisneros*, C. García-de-Alba*, A. Pardo ${ }^{\S}$ and M. Selman*
}

ABSTRACT: The pathogenesis of idiopathic pulmonary fibrosis (IPF) is probably the result of interplay between cytokines/chemokines and growth factors. The renin-angiotensin (Ang) system is involved, although its profibrotic effect is attributed to Ang II. However, recent studies suggest that renin, through a specific receptor, is implicated in fibrogenesis.

In this study, the expression of renin and renin receptor was examined in normal and IPF lungs and fibroblasts. Normal human lung fibroblasts were stimulated with renin or transfected with renin small interfering RNA (siRNA), and the expression of transforming growth factor (TGF)- $\beta 1$ and $\alpha$-1-type I collagen was analysed.

Normal lungs and lung fibroblasts expressed renin, which was strongly upregulated in IPF lungs and fibroblasts $(\sim 10$-fold increase; $p<0.05)$. Immunocytochemistry showed intense renin staining in IPF fibroblasts. Renin-stimulated lung fibroblasts displayed an increase in the expression of TGF- $\beta 1$ (mean \pm SD $1.8 \times 10^{3} \pm 0.2 \times 10^{3}$ versus $1.2 \times 10^{3} \pm 0.3 \times 10^{3}$ mRNA copies per 18 S ribosomal RNA; $p<0.01)$ and collagen $\left(5.93 \times 10^{2} \pm 0.66 \times 10^{2}\right.$ versus $3.28 \times 10^{2} \pm 0.5 \times 10^{2}$; $p<0.01$ ), while knocking down renin expression using siRNA provoked a strong decrease of both molecules. These effects were independent of Ang II, since neither losartan nor captopril decreased these effects. Renin also decreased matrix metalloprotease- 1 expression and induced TGF- $\beta 1$ activation ( $163 \pm 34$ versus $110 \pm 15$ pg active TGF- $\beta 1$ per $\mathrm{mg}$ total protein).

These findings highlight the possible role of renin as an Ang II-independent profibrotic factor in lung fibrosis.

\section{KEYWORDS: Fibroblasts, fibrosing alveolitis}

diopathic pulmonary fibrosis (IPF) is a progressive and devastating disease characterised by the expansion of the fibroblast/myofibroblast population and excessive accumulation of extracellular matrix, resulting in progressive and severe distortion of the lung architecture $[1,2]$.

Despite numerous studies performed in human disease and in experimental models, the molecular mechanisms that underlie lung fibrosis are still uncertain. Transforming growth factor (TGF)- $\beta$ seems to play a major profibrotic role, inducing fibroblast to myofibroblast differentiation and increasing collagen expression [3, 4]. However, the fibrotic lung reaction is probably the final result of a complex interplay between growth factors, cytokines and chemokines $[5,6]$.

Renin is a protease that, unlike other aspartyl proteases, has only one known substrate, angiotensinogen, which is cleaved by renin to form angiotensin (Ang) I [7]. Then, Ang-converting enzyme (ACE) converts Ang I into Ang II. The renin-Ang system is essential for the control of blood pressure and fluid homeostasis. Importantly, the existence of a local autocrine/paracrine renin-Ang system has been demonstrated, which is physiologically active in many tissues [8].

Studies in different organs, including the lung, indicate that the renin-Ang system plays an important role in fibrogenesis, although the effect is primarily attributed to the actions of Ang II through the Ang type 1 (AT1) receptor [9-12].

Recently, however, it was demonstrated that renin can directly induce a marked dose- and timedependent increase of TGF- $\beta 1$ in human and rat mesangial cells and, consequently, of various extracellular matrix components [13]. Importantly, the activation of the renin/pro-renin receptor in

This article has supplementary material available from www.erj.ersjournals.com

AFFILIATIONS

*Instituto Nacional de Enfermedades Respiratorias "Ismael Cosío Villegas",

\#Instituto Nacional de Cancerología "Instituto Nacional de Medicina Genómica,

+Unidad de Investigación Médica en Genética Humana Centro Médico S. XXI, IMSS, and

${ }^{\S}$ Facultad de Ciencias, Universidad Nacional Autónoma de México, Mexico City, Mexico.

CORRESPONDENCE

V. Ruiz

Instituto Nacional de Enfermedades Respiratorias

Tlalpan 4502

CP 14080

Mexico City

Mexico

E-mail: vicoruz@yahoo.com.mx

Received:

Aug 132010

Accepted after revision:

May 242011

First published online:

June 092011 
mesangial cells induced the synthesis of TGF- $\beta$ through Ang IIindependent mechanisms.

To date, there are no studies dealing with renin expression and activities in the lung. The aim of our study was to examine the expression of renin and renin receptor in normal and IPF lungs and fibroblasts, and evaluate the effect of renin on different fibroblast activities. Our results revealed that renin is upregulated in IPF lungs and fibroblasts, and increases collagen synthesis and TGF- $\beta$ expression.

\section{METHODS}

\section{Materials}

Antibodies for renin, extracellular signal-regulated kinase (ERK)1/2, phosphorylated ERK1/2, $\beta$-tubulin, smooth muscle $\alpha$-actin ( $\alpha \mathrm{SMA}$ ) and (pro-)renin receptor were obtained from Santa Cruz Biotechnology (Santa Cruz, CA, USA). Peroxidaseconjugated secondary antibodies were purchased from Invitrogen (Life Technologies, Grand Island, NY, USA). Captopril, losartan, radioimmunoprecipitation assay (RIPA) buffer and protease inhibitor cocktail was obtained from Biorad (Hercules, CA, USA), and phosphatase inhibitors were obtained from Sigma (St Louis, MO, USA). Recombinant human pro-renin was obtained from Cayman Chemical (Ann Arbor, MI, USA).

\section{Cell culture}

Primary human fibroblasts from IPF $(\mathrm{n}=8)$ and control lungs $(n=4)$ were obtained as previously described [14]. Fibroblasts (passages 5-8) were cultured at $37^{\circ} \mathrm{C}$ in $5 \% \mathrm{CO}_{2} / 95 \%$ air in 25 $\mathrm{cm}^{2}$ flasks containing Ham's F-12 medium supplemented with $10 \%$ fetal bovine serum, $100 \mathrm{U} \cdot \mathrm{mL}^{-1}$ penicillin, $100 \mu \mathrm{g} \cdot \mathrm{mL}^{-1}$ streptomycin and $2.5 \mathrm{mg} \cdot \mathrm{mL}^{-1}$ amphotericin $\mathrm{B}$.

\section{Western blotting}

Cells reaching $80 \%$ confluence were cultured in serum-free medium. The conditioned media were recovered, concentrated 25-fold and dialysed in columns with a 3,000-Da molecular mass limit (3000 YM; Millipore, Billerica, MA, USA). All procedures were performed in the present of the protease inhibitors 4(2-aminoethyl)benzenesulfonylfluoride hydrochloride, EDTA, bestatin, E-64, leupeptin and aprotinin (Millipore). For extraction of intracellular proteins, cells were lysed in RIPA buffer containing protease inhibitor cocktail and phosphatase inhibitors. $8 \mu \mathrm{g}$ protein was run on $7-12 \%$ sodium dodecylsulfatepolyacrylamide gel electrophoresis (SDS-PAGE) gels, followed by immunoblotting. Conditions for each antibody were performed according to the manufacturer's instructions. Protein concentration was determined by Bradford assay (Biorad).

\section{Gelatine zymography}

SDS-PAGE gels containing gelatine $\left(1 \mathrm{mg} \cdot \mathrm{mL}^{-1}\right)$ were used to identify proteins with gelatinolytic activity present in serumfree conditioned media from human lung fibroblasts stimulated with renin. Each lane was loaded with $0.3 \mu \mathrm{g}$ protein [15].

\section{Stimulation with human recombinant renin}

Normal lung fibroblasts were plated at subconfluent density in $25-\mathrm{cm}^{2}$ flasks and grown for $24 \mathrm{~h}$ in serum-free medium. The medium was then exchanged for serum-free medium containing $10 \mathrm{nM}$ human recombinant renin and the fibroblasts were cultured for a further $3 \mathrm{~h}$. Total RNA was extracted with $\mathrm{Trizol}^{\mathrm{TM}}$ (Life Technologies) and the cell supernatants were frozen at $-70^{\circ} \mathrm{C}$ until use. In parallel experiments, fibroblasts were pre-incubated with losartan or captopril at concentrations of $10 \mathrm{nM}, 1 \mathrm{~h}$ before the addition of renin. To evaluate the role of the renin receptor, in some experiments, fibroblasts were pre-incubated for $1 \mathrm{~h}$ at $37^{\circ} \mathrm{C}$ with a polyclonal anti-renin antibody (16 nM; Santa Cruz antibody sc67390).

\section{ELISA}

Active TGF- $\beta 1$ was measured in $3 \mu \mathrm{g}$ conditioned media using a commercial ELISA technique, according to the manufacturer's instructions (Emax; Promega, Madison, WI, USA).

\section{Immunocytochemistry}

Fibroblasts $\left(1 \times 10^{4}\right)$ were incubated on coverslips with serumfree medium for $24 \mathrm{~h}$. Fibroblasts were fixed with acetonemethanol (1:1) at $-20^{\circ} \mathrm{C}$ for $2 \mathrm{~min}$ and incubated with anti-human renin monoclonal antibody (Serotec, Kidlington, UK) at $37^{\circ} \mathrm{C}$ for $30 \mathrm{~min}$ followed by biotinylated goat anti-mouse immunoglobulin G for 20 min (Biogenex, San Ramon, CA, USA). 3amino-9-ethyl-carbazole (Biogenex) in acetate buffer containing $0.05 \% \mathrm{H}_{2} \mathrm{O}_{2}$ was used as substrate. Cell nuclei were counterstained with haematoxylin. Coverslips were viewed with a $1 \times 81$ microscope (Olympus, Tokyo, Japan), and images were captured using an Evolution MP camera (Media Cybernetics Inc., Bethesda, MD, USA) and processed using Photoshop (Adobe Systems Inc., San Jose, CA, USA). Image analysis was performed using Image Pro-Plus 4.5 (Media Cybernetics Inc.); quantification was expressed as pixel mean density (pmd).

\section{RT-PCR and quantitative real-time PCR amplification}

Total RNA and proteins were extracted with $\mathrm{Trizol}^{\mathrm{TM}}$, according to the manufacturer's instructions. $1 \mu \mathrm{g}$ total RNA was reverse transcribed using the Advantage RT-for-PCR kit (Clontech, Palo Alto, CA, USA). Quantitative real-time PCR amplification was performed with an i-Cycler iQ detection system (Biorad) [14]. PCR was performed with a cDNA working mixture in a $25-\mu \mathrm{L}$ reaction volume containing $3 \mu \mathrm{L}$ cDNA, PCR Master Mix $20 \times$, Taqman probes for TGF- $\beta 1$, $\alpha$ SMA, $\alpha-1$ type I collagen and renin, and $1 \mu \mathrm{L}$ of $20 \times$ Taqman 6-carboxyfluorescein-minor groove binder probes (Applied Biosystems, Foster City, CA, USA). For the renin receptor, we used primers designed from sequence GI:15011917 using Primer-BLAST (Basic Local Alignment Search Tool). The sequences were: sense $5^{\prime}$-CATTGTCCATGGGCTTCTCT-3'; and antisense 5'-GCATTCTCCAAAGGGTACGA-3'. For real-time PCR, we used SYBR ${ }_{\circledR}$ Green PCR Master Mix (Applied Biosystems) and $10 \mathrm{pmol}$ of each primer. The dynamic range was determined for each PCR product by copy number serial dilutions of $1 \times 10^{10}$ to $1 \times 10^{2}$; all PCRs were performed in triplicate. Results were expressed as the number of copies of the target gene normalised to $18 \mathrm{~S}$ ribosomal RNA (rRNA) (4352930E; Applied Biosystems).

\section{Small interfering RNA}

Small interfering RNA (siRNA) was designed as described previously $[16,17]$. The sequences of renin siRNA oligonucleotides were designed using Clontech RNAi Designer (http:// bioinfo.clontech.com/rnaidesigner/) and the homology was verified by BLAST. Two complementary oligonucleotides (Applied Biosystems) were synthesised, and were cloned into the pSIREN-retroQ-Tet vector (BD Clontech, High Wood, CA, USA) according to the manufacturer's instructions. 


\section{Transfection of packaging cells}

RetroPack PT67 cells (Clontech) were seeded into a six-well plate at $80 \%$ confluence $\left(1 \times 10^{6}\right.$ cells $\cdot$ well $\left.^{-1}\right) 24 \mathrm{~h}$ before transfection; $4 \mu \mathrm{g}$ DNA and $10 \mu \mathrm{L}$ lipofectamine 2000 were used for transfection. PT67 cells were diluted at a ratio of 1:20 and plated at $24 \mathrm{~h}$ post-transfection. The transfected PT67 cells were cultured for 10 days with $2 \mu \mathrm{g} \cdot \mathrm{mL}^{-1}$ puromycin (Clontech), and large, healthy colonies were isolated and transferred into individual wells and plates. After $24 \mathrm{~h}$, the medium was replaced and to determine the efficiency of the infection, small cellular subpopulations were treated with antibiotic. The infected cells were used for experiments or for selection as soon as possible, but not before $24 \mathrm{~h}$ post-infection. Quantitative PCR was used to verify the inhibition of renin expression. Filtered medium containing viral particles harbouring the siRNA or empty vector (Luc) siRNA $(20 \mu \mathrm{L})$ was added to fibroblasts in $2 \mathrm{~mL}$ low-glucose Dulbecco's modified Eagle's medium for infection. The infected fibroblasts were diluted at a ratio of 1:10 $24 \mathrm{~h}$ later and then puromycin was added to a final concentration of $0.5 \mu \mathrm{g} \cdot \mathrm{mL}^{-1}$. 2 weeks later, large, healthy colonies were isolated and transferred into individual wells and plates.

\section{Collagen measurement}

Collagen was quantified in conditioned medium using the Sircol collagen assay (Biocolor Ltd, Carrickfergus, UK) [18]. For

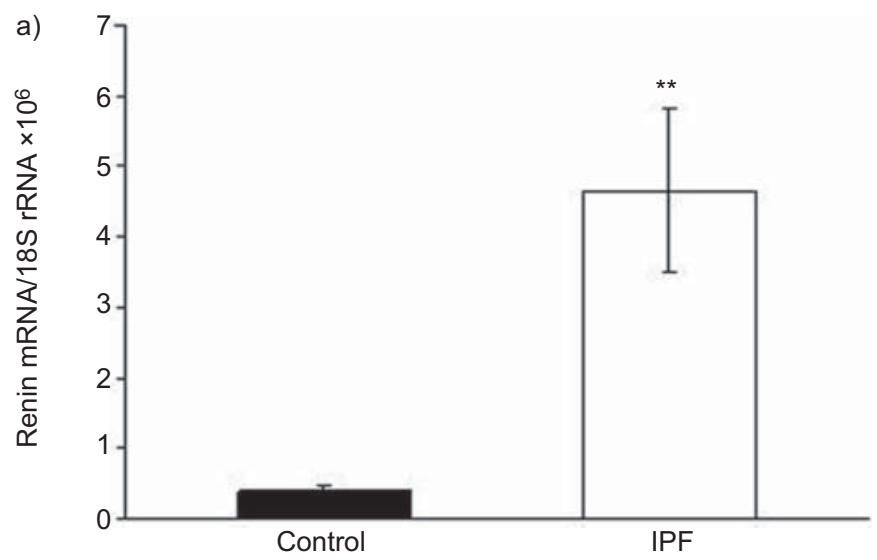

c)

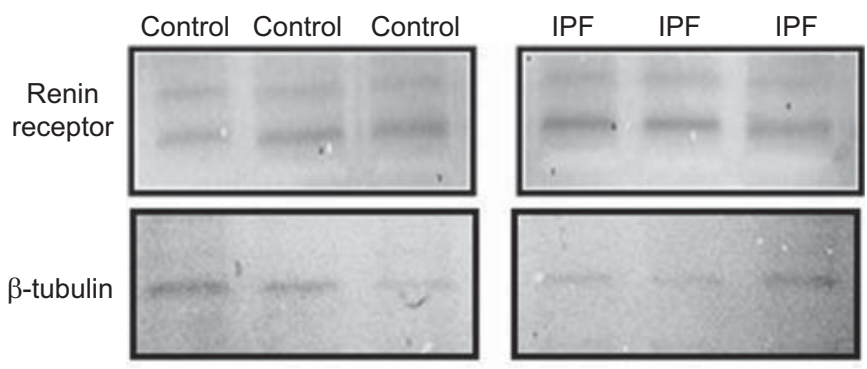

these experiments, $1 \mathrm{~mL}$ Sirius red dye was added to $100 \mu \mathrm{L}$ conditioned medium and mixed for $30 \mathrm{~min}$ at room temperature. After centrifugation at $10,000 \times g$ for $10 \mathrm{~min}$, the collagenbound dye was dissolved with $1 \mathrm{~mL}$ of $0.5 \mathrm{M} \mathrm{NaOH}$ and absorbance at $540 \mathrm{~nm}$ was measured by spectrophotometry (Nanodrop 1000; Thermo Scientific, Waltham, MA, USA).

\section{Statistical analysis}

Data are presented as mean $\pm \mathrm{SD}$. Data were analysed using unpaired t-test or by one-way ANOVA followed by Dunnett's test. Analysis of correlation was carried out with Spearman's test. A p-value $<0.05$ was considered statistically significant.

\section{RESULTS}

\section{Renin expression is increased in IPF lungs and IPF fibroblasts}

Eight IPF and four normal human lung fibroblast strains were cultured at subconfluence, and the levels of renin expression were quantified by real-time PCR. As illustrated in figure 1a, fibroblasts from IPF lungs showed a 10-fold increase in their basal levels of renin mRNA compared with normal lung fibroblasts $\left(4.7 \times 10^{6} \pm 1.2 \times 10^{6}\right.$ versus $0.4 \times 10^{6} \pm 0.1 \times 10^{6}$ renin mRNA copies per $18 \mathrm{~S}$ rRNA; $\mathrm{p}<0.01$ ). No differences were found in the expression of the renin receptor (fig. 1b), although a tendency to be higher in IPF fibroblasts was observed at the
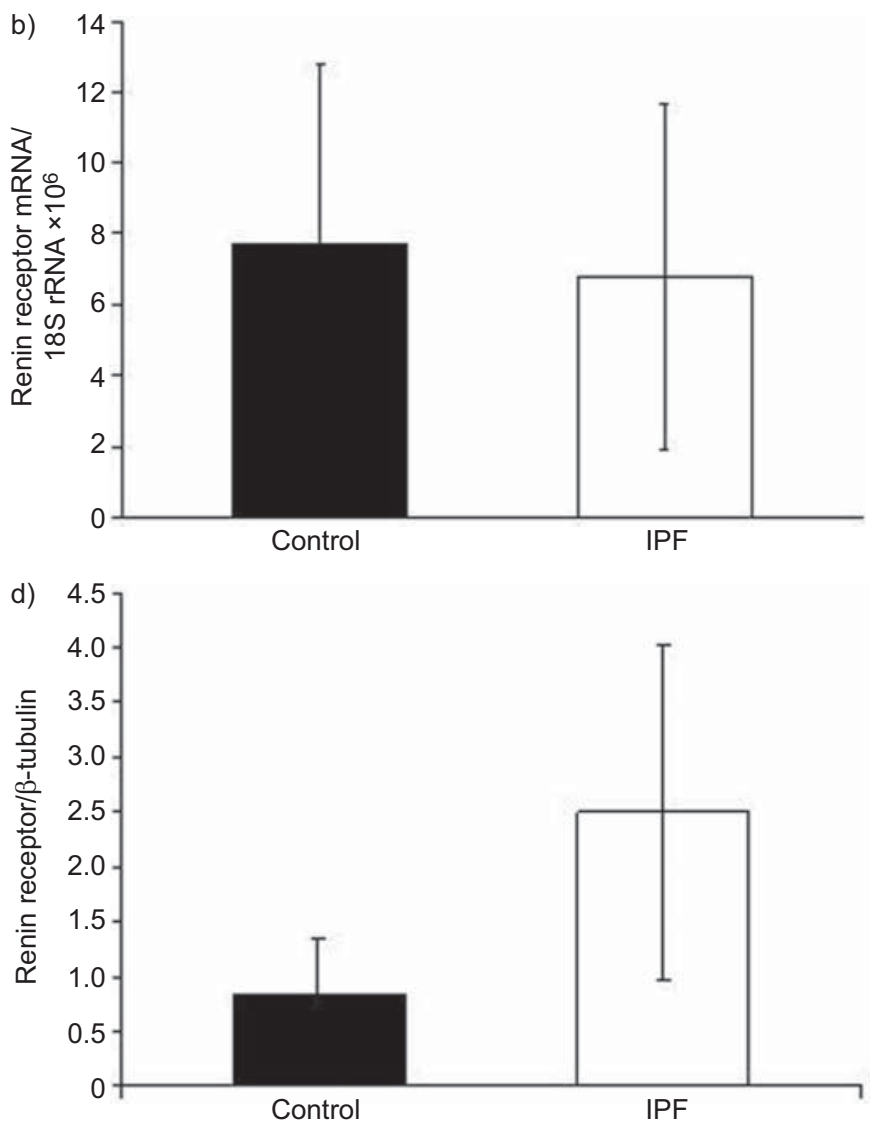

FIGURE 1. Expression of renin and renin receptor in different strains of fibroblasts. Fibroblasts were cultured to early confluence, and the expression of renin and its receptor was measured by real-time PCR. a) Renin was overexpressed in fibroblasts derived from patients with interstitial pulmonary fibrosis (IPF) ( $n=8)$ compared with fibroblasts derived from human control lungs $(n=4)$. b) No differences were detected in the expression of the renin receptor. c) Cell lysates prepared from normal and IPF lungs were analysed by Western blotting for renin receptor expression as described in the Methods section. d) No significant differences in protein level were detected by dosimetric analysis. rRNA: ribosomal RNA. **: p<0.01. 

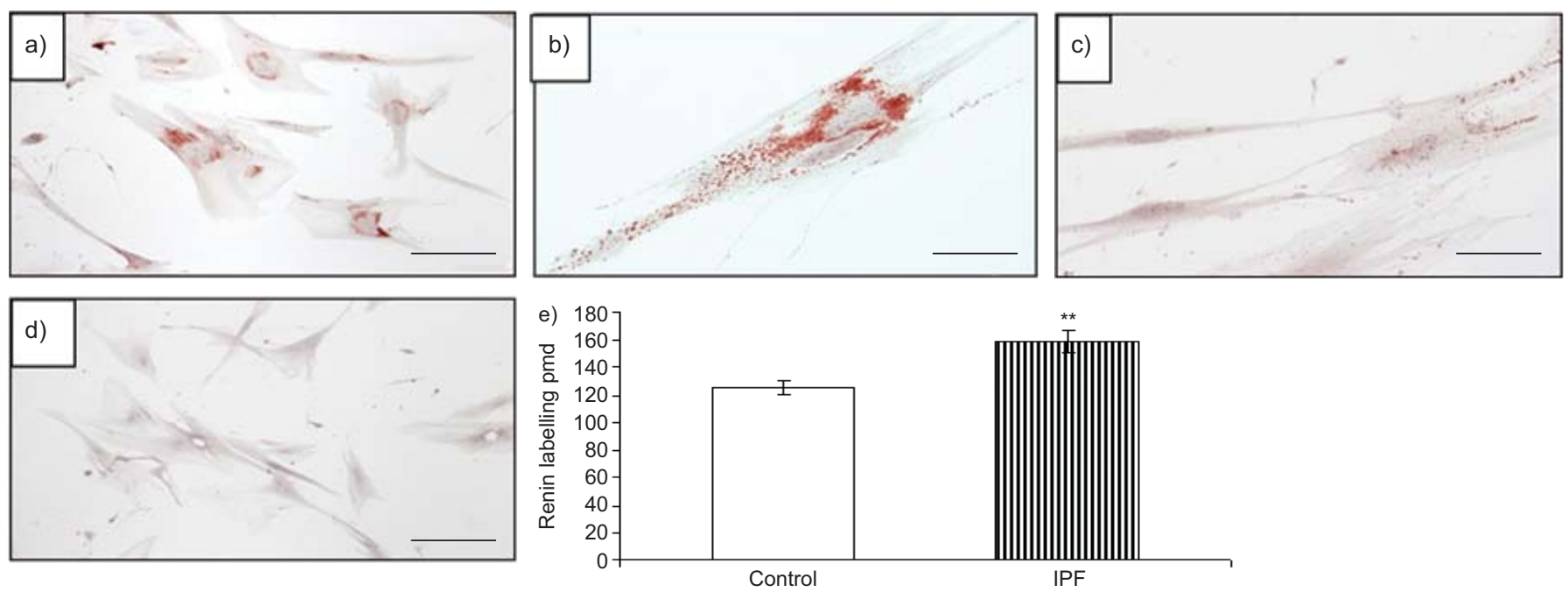

FIGURE 2. Immunocytochemical staining of renin. Fibroblasts from a, b) interstitial pulmonary fibrosis (IPF) and c) control lungs were plated on coverslips and incubated with anti-human renin monoclonal antibody. Scale bars: a) $20 \mu \mathrm{m}$; b) $5 \mu \mathrm{m}$; c) $5 \mu \mathrm{m}$. IPF fibroblasts exhibit intense cytoplasmic labelling, as is shown at higher magnification in b), while human normal lung fibroblasts exhibit a weak staining. d) Negative control in which the primary antibody was replaced by nonimmune serum (scale bar $=20 \mu \mathrm{m})$ e) Quantification of renin labelling. This figure illustrates experiments carried out in four different strains. pmd: pixel mean density. ${ }^{* *}: p<0.01$.

protein level (fig. 1c and d). The increased expression of renin by the IPF fibroblasts was confirmed at the protein level by immunocytochemistry. As exemplified in figure 2, IPF fibroblasts showed an intense cytoplasmic staining of renin that appeared to be located in the endoplasmic reticulum and Golgi apparatus. Quantitative analysis demonstrated a significant increase of renin staining in IPF fibroblasts compared with normal lung fibroblasts ( $159 \pm 4.8$ versus $125 \pm 8.4$ pmd; fig. $2 \mathrm{e})$.

Likewise, the levels of renin mRNA expression were significantly increased in IPF lungs $(n=7)$ compared with normal lungs $(n=5)\left(17.5 \times 10^{5} \pm 13.8 \times 10^{5}\right.$ versus $1.9 \times 10^{5} \pm 0.6 \times 10^{5}$ mRNA copies per $18 \mathrm{~S}$ rRNA; $\mathrm{p}<0.05$; fig. 3a). Also, the levels of renin receptor showed a tendency to be increased, although the result did not reach statistical significance $\left(185.5 \times 10^{5} \pm 193.5 \times 10^{5}\right.$ versus $20.7 \times 10^{5} \pm 8 \times 10^{5}$ renin receptor mRNA copies per $18 \mathrm{~S}$ rRNA; $p=0.06$; fig. 3b). Interestingly, there was a positive correlation between the expression of renin and the receptor; thus, the four patients with higher expression of renin also had higher expression of the receptor (Spearman $r=0.65, \mathrm{p}<0.05$ ).

\section{Renin upregulates TGF- $\beta 1$ and collagen expression through an Ang II-independent mechanism}

To evaluate putative profibrotic effects of renin, recombinant renin was used to stimulate two different normal human lung fibroblast strains, and the expression of TGF- $\beta 1$ and $\alpha-1$ type I collagen was measured by real-time PCR. As shown in figure 4, renin significantly increased the levels of both TGF- $\beta 1$ $\left(1.8 \times 10^{3} \pm 0.2 \times 10^{3}\right.$ versus $1.2 \times 10^{3} \pm 0.3 \times 10^{3}$ TGF- $\beta 1$ mRNA copies per $18 \mathrm{~S}$ rRNA; $\mathrm{p}<0.01$; fig. $4 \mathrm{a}$ ) and collagen (5.93 $\times 10^{2} \pm 0.66 \times 10^{2}$ versus $3.28 \times 10^{2} \pm 0.5 \times 10^{2} \alpha-1$ type I collagen mRNA copies per $18 \mathrm{~S}$ rRNA; $\mathrm{p}<0.01$; fig. $4 \mathrm{~b}$ ). Pre-treatment of the cells with a specific anti-renin receptor antibody abolished renin-induced collagen increase (fig. 4c). This effect was independent of Ang II, since losartan, a specific inhibitor of the receptor AT1, and captopril, an inhibitor of ACE, did not decrease the renin-induced overexpression of TGF- $\beta 1$ or collagen. When fibroblasts were stimulated with Ang II, the levels of expression of TGF- $\beta 1$ and $\alpha-1$ type I collagen were also increased (online supplementary fig. S1A and B); however, as expected, this increment was abolished by losartan. Stimulation with renin

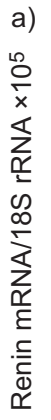

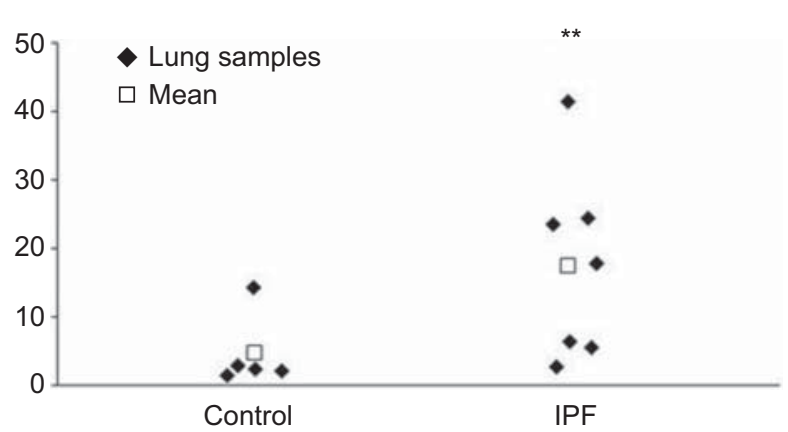

b)

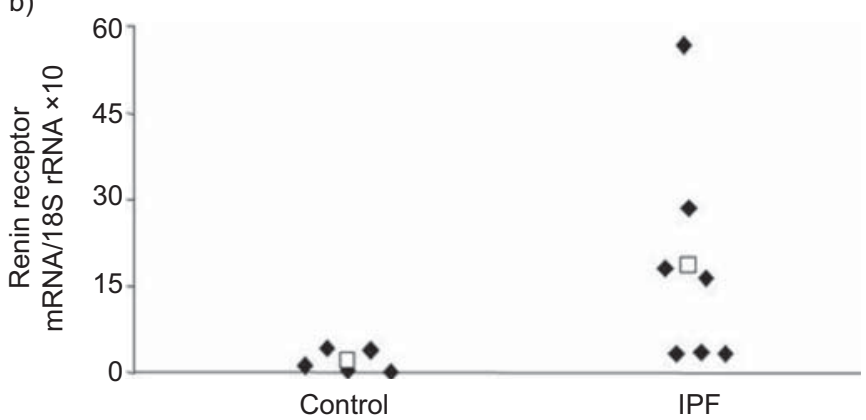

FIGURE 3. Gene expression of renin and renin receptor in interstitial pulmonary fibrosis (IPF) and normal lungs. The mRNA expression profile of renin and its receptor was assessed by quantitative real-time PCR in lung samples from controls $(n=5)$ and IPF patients $(n=7)$. a) Renin was overexpressed in the lungs derived from patients with IPF $(p<0.01)$. b) Renin receptor showed a nonsignificant tendency to be higher in IPF lungs $(p=0.06)$. rRNA: ribosomal RNA. **: $p<0.01$. 

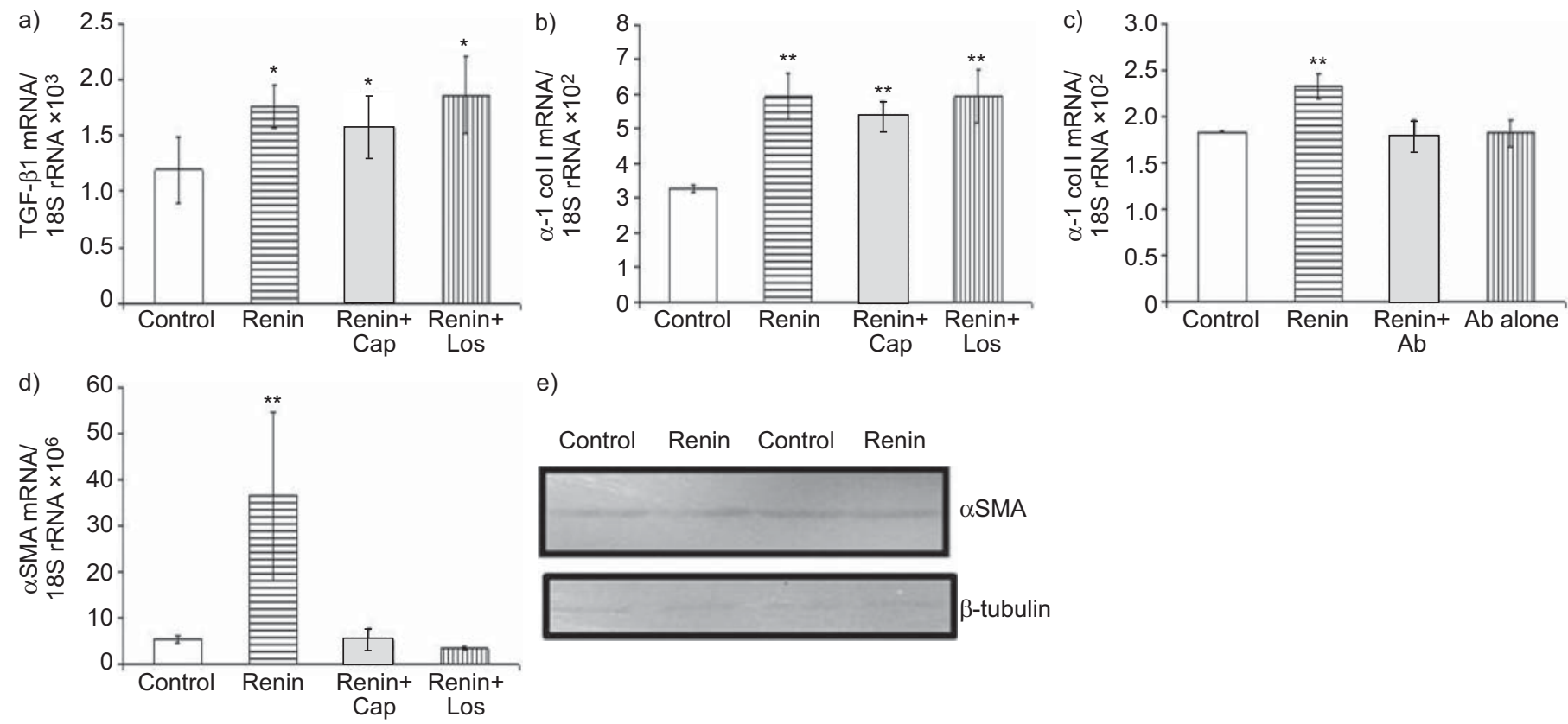

e)

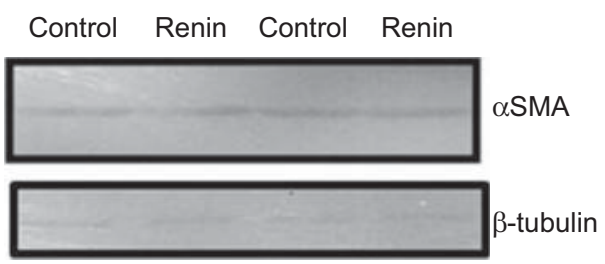

FIGURE 4. Renin upregulates transforming growth factor (TGF)- $\beta 1$ and $\alpha-1$ type I collagen (col I) gene expression. Human lung fibroblasts stimulated with $10 \mathrm{nM}$ recombinant renin showed a significant increase in a) TGF- $\beta 1$ and b) $\alpha-1$ col I. Treatment with losartan (Los) and captopril (Cap) did not reverse this effect. c) The increase of collagen expression was blocked by a specific anti-renin receptor antibody. d) Smooth muscle $\alpha$-actin ( $\alpha$ SMA) mRNA levels were determined by quantitative RT-PCR analysis and e) the protein levels by Western blotting analysis. Results represent the average of two independent experiments with different fibroblast strains, each performed in triplicate. rRNA: ribosomal RNA. *: $p<0.05 ; * *: p<0.01$.

also increased the expression of $\alpha \mathrm{SMA}$ (fig. 4d), although this result was not confirmed at the protein level (fig. 4e).

\section{Renin decreases matrix metalloprotease 1 expression but has no effect on matrix metalloprotease 2}

Human lung fibroblasts were treated with renin, and the expression of matrix metalloprotease (MMP)-1 and MMP-2, two enzymes that have been associated with the pathogenesis of IPF, was examined [19]. Stimulation with renin caused a significant decrease in the expression of MMP-1 (fig. 5a), while it showed no effect on MMP-2 expression (fig. 5b) or activity (fig. 5c).

It has been suggested that the effect of renin is mediated by ERK1/2 [13]. To investigate whether the stimulation of human lung fibroblasts by renin activated the ERK1/2 signalling pathway, total and phosphorylated ERK1/2 were quantified in cell extracts by Western blot. As illustrated in figure $6 a$ and $b$, treatment of fibroblasts with renin strongly stimulated phosphorylation of ERK1/2. The temporal profile of ERK1/2 activation showed an increase that reached a plateau at 20$30 \mathrm{~min}$, with a gradual decline thereafter.

\section{Renin induces TGF- $\beta 1$ activation through an Ang II-independent mechanism}

Two different normal human lung fibroblast cell lines were stimulated with renin and the levels of active TGF- $\beta 1$ were assessed in the conditioned medium by ELISA. As shown in figure $6 \mathrm{c}$, renin stimulation significantly increased the levels of
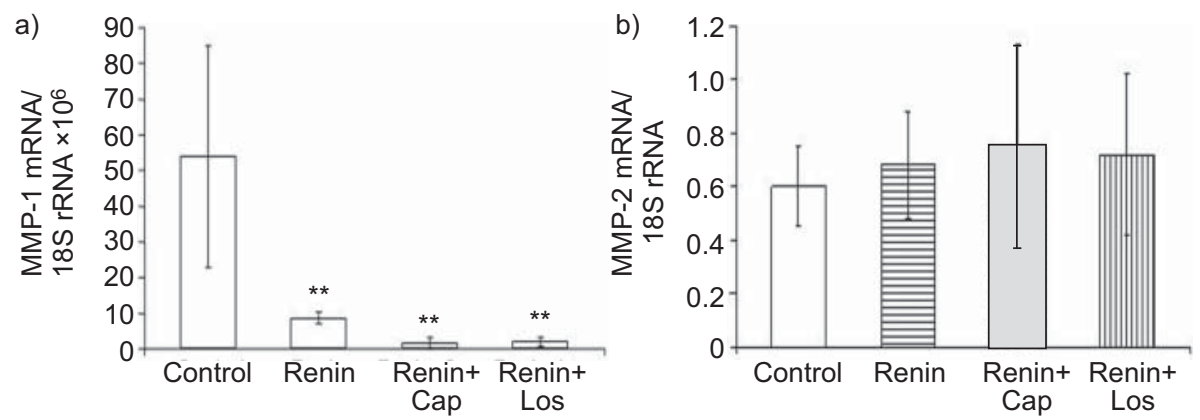

c)

FIGURE 5. Renin downregulates matrix metalloprotease (MMP)-1 expression but has no effect on MMP-2. a) Human lung fibroblasts stimulated with $10 \mathrm{nM}$ recombinant renin displayed a significant decrease in the expression of MMP-1. b) Gene expression of MMP-2 was not modified. c) By zymography, no changes were observed in the proMMP-2 and MMP-2 gelatinolytic activity bands. Results represent two independent experiments with different fibroblast strains, each performed in triplicate. rRNA: ribosomal RNA; Cap: captopril; Los: Iosartan. **: $p<0.01$. 
a)

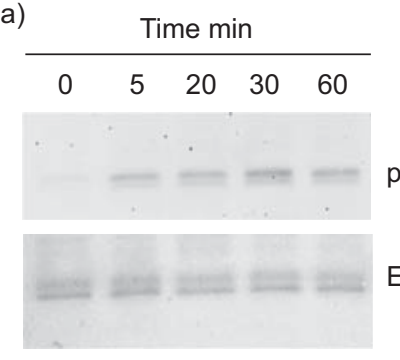

b) 2000

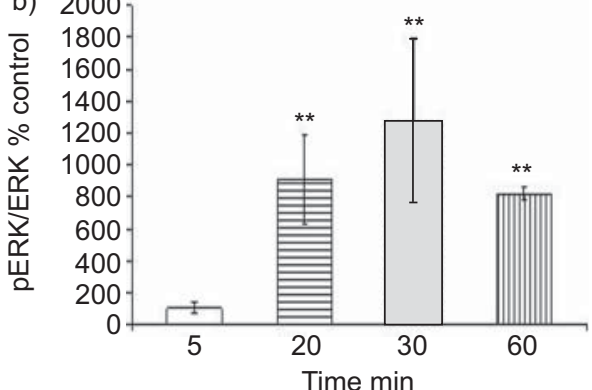

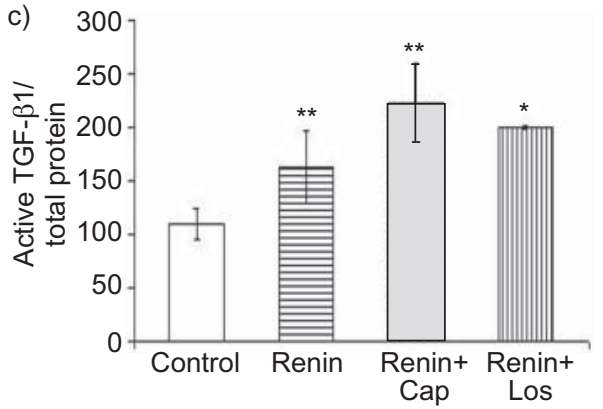

FIGURE 6. Renin activates extracellular signal-regulated kinase (ERK)1/2 phosphorylation and increases active transforming growth factor (TGF)- $\beta 1$. Human lung fibroblasts were stimulated with $10 \mathrm{nM}$ recombinant renin. a) Western blotting and b) corresponding densitometric analysis of total and phosphorylated ERK1/2 (pERK1/2), demonstrating that renin induces ERK1/2 phosphorylation. c) A significant increase in active TGF- $\beta 1$ was observed, an effect that was not reversed by captopril (Cap) or Iosartan (Los). Results represent the average of two independent experiments with different fibroblast strains, each performed in triplicate. ${ }^{*}: p<0.05 ;{ }^{* *}: p<0.01$.

active TGF- $\beta 1$, which was not affected by the ACE inhibitor or the AT1 receptor blocker.

\section{Silencing renin induces a marked decrease of TGF- $\beta$ and collagen expression}

To determine the significance of a loss of renin on fibroblast behaviour, human normal lung fibroblasts were transiently transfected with renin siRNA. With the siRNA, we achieved $\sim 75 \%$ silencing of renin, as measured by PCR (fig. 7a); this decrease was confirmed at the protein level by Western blotting of conditioned media (fig. $7 \mathrm{~b}$ ). Real-time PCR was used to determine the effect of renin siRNA on TGF- $\beta$, collagen and $\alpha$ SMA expression. As shown in figure 7c, compared with the levels observed in normal fibroblasts and fibroblasts treated with the virus packaged with the empty Luc construct, silencing of renin caused a significant decrease in the expression of TGF$\beta 1$ (control $1.84 \times 10^{2} \pm 0.48 \times 10^{2}$, Luc $1.26 \times 10^{2} \pm 0.42 \times 10^{2}$ and renin siRNA $0.42 \times 10^{2} \pm 0.24 \times 10^{2}$ TGF- $\beta 1$ mRNA copies per $18 \mathrm{~S}$ rRNA; $\mathrm{p}<0.01)$.

Collagen expression was also significantly decreased at the mRNA (control $5.2 \times 10^{2} \pm 0.6 \times 10^{2}$, Luc $4.7 \times 10^{2} \pm 0.11 \times 10^{2}$ and renin siRNA $0.74 \times 10^{2} \pm 0.4 \times 10^{2} \alpha-1$ type I collagen mRNA per $18 \mathrm{~S}$ rRNA; $\mathrm{p}<0.01$ ) and protein levels, where the inhibition of the expression of renin provoked $\sim 50 \%$ decrease of secreted collagen in the fibroblast-conditioned media (fig. 8a and b). $\alpha \mathrm{SMA}$ expression did not show changes (data not shown).

\section{DISCUSSION}

The development of IPF and other fibrotic lung disorders involves the activation of fibroblasts, their differentiation to myofibroblasts and the exaggerated production of extracellular matrix proteins, with subsequent aberrant architectural remodelling. The pathogenesis of IPF, the most aggressive interstitial lung disease, is believed to be related to dysregulated cross-talk between epithelial cells and fibroblasts, and mediated by a complex interplay among various cytokines, chemokines and growth factors, with a central role of TGF- $\beta$. In this context, several studies have implicated the renin-Ang system in lung fibrogenesis, but its profibrotic effects have been attributed primarily to Ang II [20].

Our results demonstrate, for the first time, that human lungs express renin and that this expression is strongly upregulated in IPF lung tissues. Likewise, IPF fibroblasts showed a 10-fold increase of renin expression and displayed an intense cytoplasmic immunoreactive renin signal compared with normal human lung fibroblasts. However, the results of our in vitro experiments support a profibrotic role of renin, since stimulation of human lung fibroblasts with renin induced the overexpression of

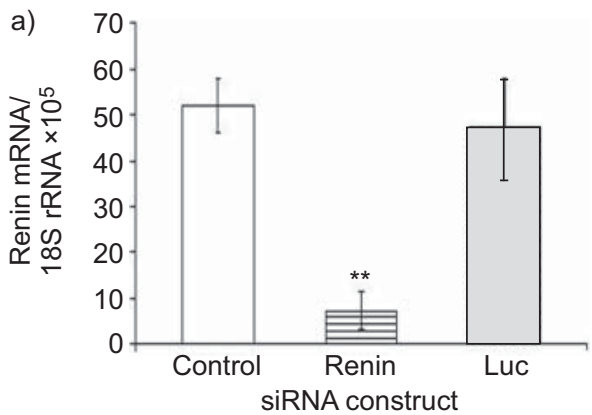

b)

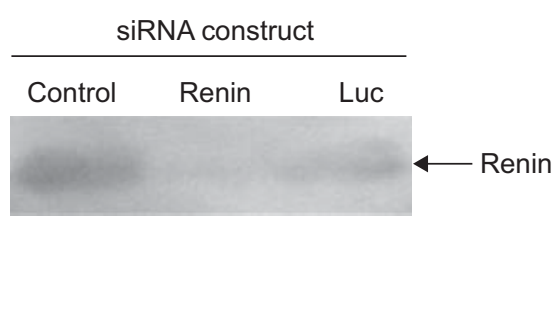

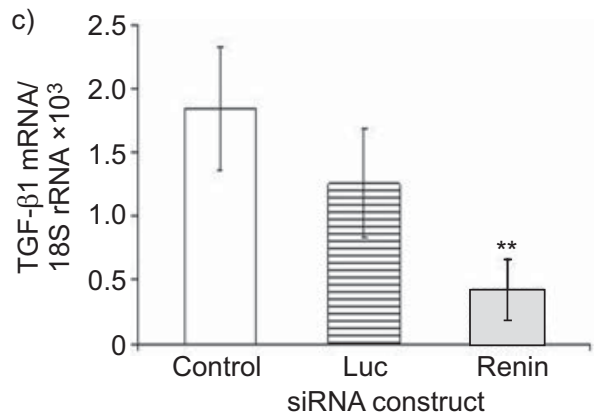

FIGURE 7. Renin silencing by small interfering RNA (siRNA) causes downregulation of transforming growth factor (TGF)- $\beta 1$. Human lung fibroblasts were treated with virus containing renin siRNA or empty vector (Luc). siRNA caused a significant reduction of renin expression at a) the RNA and b) the protein levels. c) Cells treated with renin siRNA displayed a significant reduction of TGF- $\beta 1$. Results represent two independent experiments performed with one transfected fibroblast strain in triplicate. rRNA: ribosomal RNA.**: $p<0.01$ 

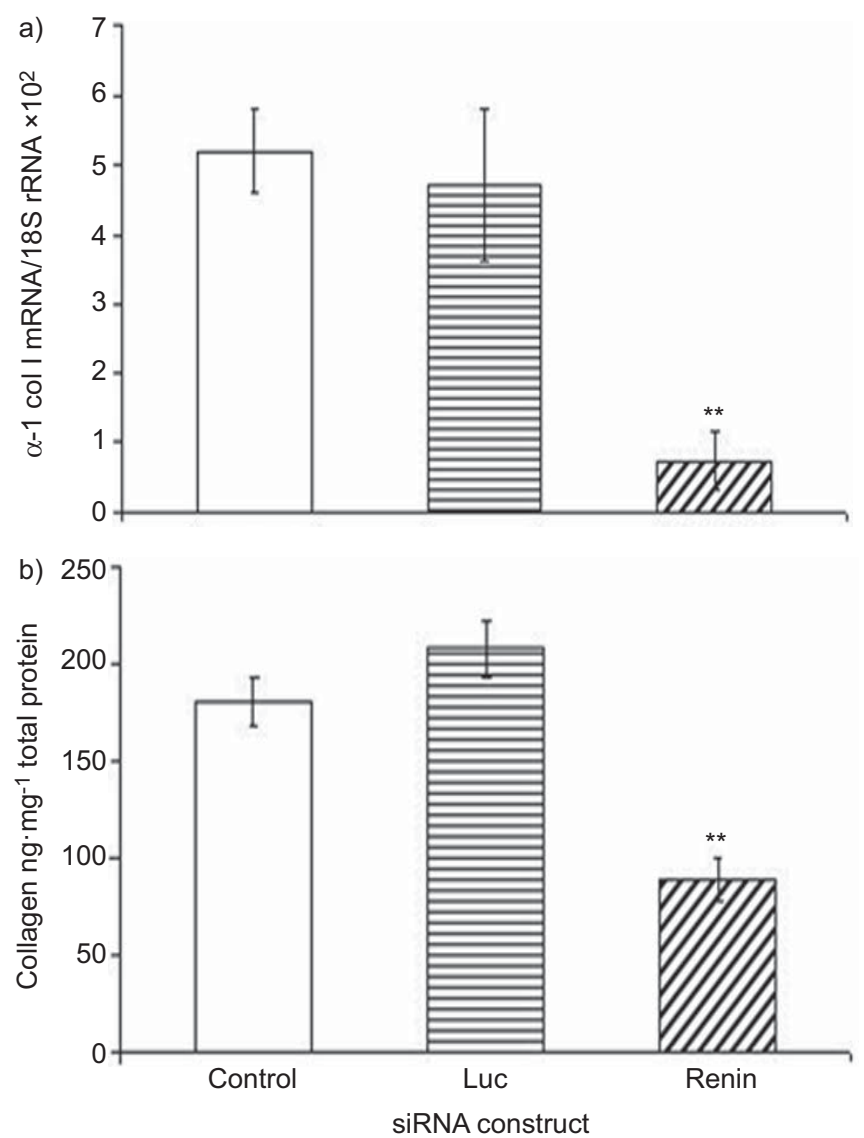

FIGURE 8. Effect of downregulation of renin on collagen production. Human lung fibroblasts were treated with renin small interfering RNA (siRNA), and a) $\alpha-1$ type I collagen (col I) gene expression was examined by real-time PCR and b) collagen protein levels were measured in the conditioned medium using the Sircol collagen assay (Biocolor Ltd, Carrickfergus, UK). Downregulation of renin caused a significant decrease of collagen synthesis. Results represent two independent experiments performed with one transfected fibroblast strain in triplicate. rRNA: ribosomal RNA; Luc: empty vector. ${ }^{* *}: p<0.01$

TGF- $\beta$, a pivotal fibrogenic factor, and of collagen, the main component of the fibrotic scar. Our results also showed that normal human fibroblasts stimulated with renin release increased amounts of active TGF- $\beta 1$. Interestingly, renin also provoked a decrease of MMP-1, an effect that is also observed when fibroblasts are treated with TGF- $\beta$ [21]. Moreover, knocking down renin expression using siRNA caused an important decrease of the basal expression of TGF- $\beta 1$ and collagen; however, this did not affect basal $\alpha$ SMA expression. A similar effect was described in mesangial cells, where it was found that the targeting of the renin receptor with siRNA abolished renininduced upregulation of TGF- $\beta 1$, indicating a direct effect through this receptor [13].

Our understanding of the renin and renin-Ang systems has evolved considerably over the last few years. Thus, the reninAng system, which has traditionally been viewed as circulatory system specific, may also act locally, and recent evidence indicates that a complete, functional renin-Ang system exists within cells [22]. However, the physiological role of this system and its implications in tissue pathology remain to be determined.
Recently, identification of a specific 350 amino acid protein, (pro-)renin receptor, has increased the complexity of the system. Although renin was previously considered only as an enzyme responsible for the cleavage of angiotensinogen to form Ang I, a growing body of evidence indicates that renin and pro-renin binding to the receptor trigger intracellular signalling that, in turn, modifies gene expression [23]. Thus, renin exhibits novel receptor-mediated actions, independent of Ang II, which appear to be mediated by extracellular ERK1/2 of the mitogen-activated protein kinase pathway [24-26]. In this context, our results also demonstrated that renin stimulation induces a substantial activation of ERK1/2 in human lung fibroblasts, corroborating the role of this pathway in the upregulation of profibrotic genes, such as those encoding TGF- $\beta 1$ and collagen. Importantly, recent evidence indicates that the (pro-)renin receptor binds both renin and its inactive precursor pro-renin, and their binding triggers intracellular signalling that upregulates the expression of fibrogenic mediators [27]. In our study, we also measured the levels of the renin receptor in both lungs and fibroblasts and, although we observed a tendency towards increased expression in the IPF lungs and fibroblasts, the results did not reach statistical difference. However, an interesting observation was a strong correlation in the IPF lungs between the expression of renin and of its receptor.

Previous studies have suggested that renin may play a profibrotic role in vivo, as it has been demonstrated in the clipped kidney of Goldblatt rats treated for hypertension [28]. However, studies in other organs, including the lungs, are scant. As in other tissues, Ang II has typically been considered the main effector of the renin-Ang system in lung repair and remodelling. Thus, it has been shown that Ang II causes apoptosis of alveolar epithelial cells and is a potent inducer of pro-collagen production by human lung fibroblasts both effects via activation of the type 1 receptor and, at least in part, via the autocrine action of TGF- $\beta$ [29-31]. Nevertheless, our findings demonstrated that renin has a direct effect on human lung fibroblasts, since inhibition of Ang II by losartan or of ACE by captopril had a minimal or no effect on the renin-induced upregulation of the fibrotic mediators TGF- $\beta 1$ and collagen. These results clearly support the notion that in lung mesenchymal cells, renin is able to induce the upregulation of profibrotic molecules through an Ang II-independent pathway.

In a recent study, primary human mesangial cells isolated from healthy kidneys were used to evaluate the renin- and prorenin-triggered gene expression profiles. It was shown that both have a similar transcriptional signature that is independent of Ang production. Importantly, the changes in gene expression induced by renin and pro-renin were consistent with the development of organ damage and fibrosis, primarily through TGF- $\beta$ mechanisms [32].

Our findings and the aforementioned studies in kidney fibrosis indicate that renin by itself may play an important role in extracellular matrix accumulation and suggest that the inhibition of the (pro-)renin/receptor system may decrease the release of fibrillar collagens and fibrotic factors, such as TGF- $\beta$. In this context, it was recently demonstrated that aliskiren, an orally effective, direct renin inhibitor, markedly prevented cardiac hypertrophy, inflammation and fibrosis, and renal 
glomerulosclerosis caused by cuff injury in endothelial nitric oxide synthase-deficient mice [33]. In our study, targeted renin gene silencing by siRNA in cultured human lung fibroblasts ameliorated the expression of collagen and TGF- $\beta 1$ expression.

In summary, our findings highlight the possible role of renin as an Ang II-independent profibrotic factor in lung fibrosis. IPF is by far the most aggressive interstitial lung disease, and most patients die from this disorder within a few years of diagnosis. While the pathogenic mechanisms are incompletely understood, the disease is probably the result of the abnormal expression and regulation of a variety of genes that arise from a combination of individual susceptibility and environmental triggers. The results of our study indicate that renin can be one of the mediators involved in the pathogenesis of this disorder.

\section{SUPPORT STATEMENT}

This work was partially supported by Consejo Nacional de Ciencia y Tecnología grant III 89442.

\section{STATEMENT OF INTEREST}

None declared.

\section{REFERENCES}

1 Gross TJ, Hunninghake GW. Idiopathic pulmonary fibrosis. $N$ Engl J Med 2001; 345: 517-525.

2 Selman M, King TE, Pardo A. Idiopathic pulmonary fibrosis: prevailing and evolving hypotheses about its pathogenesis and implications for therapy. Ann Intern Med 2001; 134: 136-151.

3 Willis BC, Borok Z. TGF- $\beta$-induced EMT: mechanisms and implications for fibrotic lung disease. Am J Physiol Lung Cell Mol Physiol 2007; 293: L525-L534.

4 Gauldie J, Bonniaud P, Sime P, et al. TGF- $\beta$, Smad 3 and the process of progressive fibrosis. Biochem Soc Trans 2007; 35: 661-664.

5 Agostini C, Gurrieri C. Chemokine/cytokine cocktail in idiopathic pulmonary fibrosis. Proc Am Thorac Soc 2006; 3: 357-363.

6 Strieter RM, Gomperts BN, Keane MP. The role of CXC chemokines in pulmonary fibrosis. J Clin Invest 2007; 117: 549-556.

7 Persson PB. Renin: origin, secretion and synthesis. J Physiol 2003; 552: 667-671.

8 Lavoie JL, Sigmund CD. Minireview: overview of the reninangiotensin system - an endocrine and paracrine system. Endocrinology 2003; 144: 2179-2183.

9 Hartner A, Porst M, Klanke B, et al. Angiotensin II formation in the kidney and nephrosclerosis in Ren-2 hypertensive rats. Nephrol Dial Transplant 2006; 21: 1778-1785.

10 Bataller R, Sancho-Bru P, Ginès P, et al. Liver fibrogenesis: a new role for the renin-angiotensin system. Antioxid Redox Signal 2005; 7: 1346-1355.

11 Li X, Rayford H, Uhal BD. Essential roles for angiotensin receptor AT1a in bleomycin-induced apoptosis and lung fibrosis in mice. Am J Pathol 2003; 163: 2523-2530.

12 Marshall RP, Gohlke P, Chambers RC, et al. Angiotensin II and the fibroproliferative response to acute lung injury. Am J Physiol Lung Cell Mol Physiol 2004; 286: L156-L164.

13 Huang $\mathrm{Y}$, Wongamorntham S, Kasting J, et al. Renin increases mesangial cell transforming growth factor- $\beta 1$ and matrix proteins through receptor-mediated, angiotensin II-independent mechanisms. Kidney Int 2006; 69: 105-113.

14 Ramos C, Montaño M, Becerril C, et al. Acidic fibroblast growth factor decreases $\alpha$-smooth muscle actin expression and induces apoptosis in human normal lung fibroblasts. Am J Physiol Lung Cell Mol Physiol 2006; 291: L871-L879.

15 García-de-Alba C, Becerril C, Ruiz V, et al. Expression of matrix metalloproteases by fibrocytes: possible role in migration and homing. Am J Respir Crit Care Med 2010; 182: 1144-1152.

16 Liu FY, Xiao L, Peng YM, et al. Inhibition effect of small interfering RNA of connective tissue growth factor on the expression of vascular endothelial growth factor and connective tissue growth factor in cultured human peritoneal mesothelial cells. Chin Med J 2007; 120: 231-236.

17 Pebernard S, Iggo RD. Determinants of interferon-stimulated gene induction by RNAi vectors. Differentiation 2004; 72: 103-111.

18 Distler JH, Jüngel A, Caretto D, et al. Monocyte chemoattractant protein 1 released from glycosaminoglycans mediates its profibrotic effects in systemic sclerosis via the release of interleukin-4 from T cells. Arthritis Rheum 2006; 54: 214-225.

19 Pardo A, Selman M, Kaminski N. Approaching the degradome in idiopathic pulmonary fibrosis. Int J Biochem Cell Biol 2008; 40: 1141-1155.

20 Antoniu SA. Targeting the angiotensin pathway in idiopathic pulmonary fibrosis. Expert Opin Ther Targets 2008; 12: 1587-1590.

21 Eickelberg O, Köhler E, Reichenberger F, et al. Extracellular matrix deposition by primary human lung fibroblasts in response to TGF$\beta 1$ and TGF- $\beta 3$. Am J Physiol 1999; 276: L814-L824.

22 Kumar R, Singh VP, Baker KM. The intracellular renin-angiotensin system: a new paradigm. Trends Endocrinol Metab 2007; 18: 208-214.

23 Nguyen G, Danser AH. Prorenin and (pro)renin receptor: a review of available data from in vitro studies and experimental models in rodents. Exp Physiol 2008; 93: 557-563.

24 Huang Y, Noble NA, Zhang J, et al. Renin-stimulated TGF- $\beta 1$ expression is regulated by a mitogen-activated protein kinase in mesangial cells. Kidney Int 2007; 72: 45-52.

25 Huang J, Siragy HM. Regulation of (pro)renin receptor expression by glucose-induced mitogen-activated protein kinase, nuclear factorКB, and activator protein-1 signaling pathways. Endocrinology 2010; 151: 3317-3325.

26 Campbell DJ. Critical review of prorenin and (pro)renin receptor research. Hypertension 2008; 51: 1251-1264.

27 Cousin C, Bracquart D, Contrepas A, et al. Potential role of the (pro)renin receptor in cardiovascular and kidney diseases. J Nephrol 2010; 23: 508-513.

28 Krebs C, Hamming I, Sadaghiani S, et al. Antihypertensive therapy upregulates renin and (pro)renin receptor in the clipped kidney of Goldblatt hypertensive rats. Kidney Int 2007; 72: 725-730.

29 Wang R, Ramos C, Joshi I, et al. Human lung myofibroblastderived inducers of alveolar epithelial apoptosis identified as angiotensin peptides. Am J Physiol 1999; 277: L1158-L1164.

30 Marshall RP, Gohlke P, Chambers RC, et al. Angiotensin II and the fibroproliferative response to acute lung injury. Am J Physiol Lung Cell Mol Physiol 2004; 286: L156-L164.

31 Papp M, Li X, Zhuang J, et al. Angiotensin receptor subtype $\mathrm{AT}_{1}$ mediates alveolar epithelial cell apoptosis in response to ANG II. Am J Physiol Lung Cell Mol Physiol 2002; 282: L713-L718.

32 Melnyk RA, Tam J, Boie Y, et al. Renin and prorenin activate pathways implicated in organ damage in human mesangial cells independent of angiotensin II production. Am J Nephrol 2009; 30: 232-243.

33 Yamamoto E, Kataoka K, Dong YF, et al. Aliskiren enhances the protective effects of valsartan against cardiovascular and renal injury in endothelial nitric oxide synthase-deficient mice. Hypertension 2009; 54: 633-638. 